ISSN: 2716-1277

e-ISSN: 2716-1269

Available online at

https://jlic.iain-jember.ac.id/
Journal of Language Intelligence and Culture

Fakultas Tarbiyah dan Ilmu Keguruan

IAIN Jember

Vol 2, No.1, Page 77-90, June 2020

\title{
Correlation between Beliefs on Translation and the Use of It as an English Learning Strategy
}

\author{
Mega Fariziah Nur Humairoh \\ IAIN Jember \\ megahumairoh2o@gmail.com \\ Febrina Rizky Agustina \\ IAIN Jember \\ nec.febrina@gmail.com
}

\section{ARTICLE INFO \\ Article History: \\ Accepted: March 2020. \\ Approved: May 2020. \\ Published: June 2020 \\ Key Words: \\ Translation as a Learning Strategy, Students' Beliefs, The Use of Translation}

DOI: $10.35719 /$ jlic.v2i1.21

\begin{abstract}
This current study focuses its investigation on the correlation between students' beliefs about the use of translation as an English learning strategy and the strategic use of translation in learning English by EFL students in Indonesia. This current study is aimed 1) to investigate the correlation between students' beliefs and the use of translation as a learning strategy 2) to examine the developmental of the use of translation as a learning strategy across different year of study. One hundred seventeen undergraduate students, consisting 67 freshmen and 50 sophomores participated in this correlational study. The data were collected by frequency of an Indonesian Version of the Inventory for Beliefs about Translation for beliefs measurement and the Inventory for Translation as a Learning Strategy. Correlation and t-test were employed in the study. Correlation analysis reveals that a strong positive correlation between students' beliefs about translation and their use of translation as learning strategy. T-test finds the significant difference in the use of translation as learning strategy between freshman and sophomore learner.
\end{abstract}

\section{INTRODUCTION}

Translation as a learning strategy is still long-standing issue and on-going controversy in language learning. Translation remains disputable whether the use of translation should be encouraged or 


\section{JLIC}

not. Some teachers consider it as a way to help students' learning while others neglect the use of translation strategy in the class. However, despite recent objection related to the use of translation in learning English as a foreign language, in reality it shows the reverse. The Indonesian translation strategy is believed being used by Indonesian English Foreign Learners (EFL) students in all levels of education. Indonesian EFL students frequently use translation to facilitate English language learning and to acquire English language. It is because language learning is not merely a translation from English to Indonesian, but translation is used by language learners as a learning strategy.

Considering translation as an EFL learning strategy, translation can be used as an effective medium for developing students' English competence. Students receive, process, and transfer the target language based on the mother tongue. Early studies about language learning strategies base their argument on the findings that of the 11 cognitive strategies identified by the researchers, translation was employed as a regularly used cognitive strategy (11.3\%, ), (O’Malley, Chamot, Stewner Manzanares, Kupper, \& Russo, 1985, p.43) as an effective tool in learning vocabulary (Prince, 1996, pp. 478-493). Another finding showed that Iranian students make use of translation as a strategy to help them learn English in language learning process (Karimian, 2013, pp.605-610). Hence, translation is considered as a supporting factor in language learning in order to improve students' language learning. In other words, students employed translation strategy to assist them to improve their knowledge of English and solve their language problems.

The result of her research is consistent with Brooks-Lewis' survey (2009, pp. 216-235), learners' positive attitudes towards the use of their native language in the FL classroom in Mexico. After accomplishment of an EFL course, participants wrote their perceptions and showed positive response to the inclusion of the L1 because it had been beneficial to their foreign language learning experience. 
In line with these previous researches, the newest one comes from Aktein \& Glienecki (2015), for instance, reported that translation plays an important facilitative role in ELT students' English learning experiences. It can be said that translation is able to be a great tool for students to grasp meaning of their foreign language.

In terms of the relationship between learners' beliefs and their strategy use, Wenden (1987) study illustrated how beliefs affected learners' choice of strategies, their attending pattern, criteria for evaluating the effectiveness of a language learning activity, and their planning priorities. Besides, Liao (2006) stated that although individual variations did occur, overall, students' professed beliefs on the IBT were greatly consistent with their described learning strategies on the ITLS.

There have varied opinions by early studies in term of stage of the use of translation which is most beneficial for students. Aktein \& Glienecki (2015) confirmed that with respect to students' shared beliefs about using translation in learning English, generally they expressed that the translation is an assisting tool for present phase of learning (Intermediate level), and considered translation as a positive learning resource for them to comprehend, memorize, and produce better English, to acquire English skills, and to complete various English tasks. Husain's research (1995) suggested that using translation had highly positive effects on the low and intermediate proficiency learners, but it did not benefit higher level students. The researcher found that translation strategy could enhance English learning in general. Chia and Chia (2001) studies that less proficient English learners more frequently employed or benefited from translation strategies than their counterparts who were more proficient learners of English, but did not corroborate the results of Liao (2006 ) study that found no significant relationship between these variables.

According to Ross in Kavaliauskienë \& Kaminskienë, (2007) stated that Translation holds a special importance at an intermediate and advanced level: in the advanced or final stage of 


\section{JLIC}

language teaching, translation from $\mathrm{L}_{1}$ to $\mathrm{L}_{2}$ and $\mathrm{L}_{2}$ to $\mathrm{L}_{1}$ is recognized as the fifth skill and the most important social skill since it promotes communication and understanding between strangers". It means that the level of the study may affect the students' use of translation as a learning strategy.

Despite numbers of researchers have considered the positive potential of using translation in language learning, a gap seems noticeable that none of recent publication has indicated a renew attention of using translation in language learning particularly students' beliefs about translation and their frequent use of translation as an English learning strategy in Indonesian EFL context. Most studies are carried out to examine the students' beliefs of using translation in English learning applied by Asian or Western students and none of Indonesian students as the subjects of the study.

Therefore, it turns into a good opportunity for researcher to grasp this challenge. It is purposed to know the relationship between students' beliefs about translation and their use of translation as English learning strategy. In addition, it attempts to analyze undergraduate students' use of translation between freshman and sophomore students on their frequency use in Indonesian translation in learning English.

\section{METHODS}

Based on the research objectives, this study contained correlational and comparative elements. Therefore, the first is in the form of the correlation between students' beliefs about translation as learning strategy and the use of it and the latter is in the form of a comparison between freshman and sophomore in their use of translation as a learning strategy in learning English. This research was conducted at Institut Agama Islam Negeri (IAIN) Jember. The spread of questionnaires actually has been targeted for 128 participants (students) across two levels. However, only 117

participants (students) responded completely. Most of the respondents preferred not to write their name and remain 
anonymous.A total of 117 subjects were undergraduate students in English Department at IAIN Jember. It consisted of $50(42.7 \%)$ freshman students and $67(45 \%)$ sophomore students totalling 117 students. The university was selected on the basis of accessibility and ease of bureaucracy. The participants were requested to complete two sets of questionnaires concerning students' beliefs and translation as learning strategy which are the Inventory for Beliefs about Translation (IBT) for beliefs measurement that was consisted 24 items and the Inventory for Translation as a Learning Strategy (ITLS) for strategy use measurement that was consisted of 28 items developed by Liao (2006). In both questionnaires, the participants were asked to assess their beliefs about translation as learning strategy in learning English and their frequency use on a five-point Likert scale ranging from 1, which means (1) strongly disagree, (2) disagree, (3) neither agree nor disagree, (4) agree, or (5) strongly agree. It was applied for the first instrument IBT questionnaire. Meanwhile, the second instrument ITLS also applied the same scale by indicating to which they often use translation as their learning strategy in learning English with each statement using (1) never, (2) seldom, (3) sometimes, (4) often, or (5) almost always.This research used good instruments that had been met satisfactorily the requirements as instruments. These requirements were validity and reliability of the instruments has been tested. The results of validity test indicate that there was a significant correlation at 0.05 levels between all the items in both Questionnaires and total subjects' scores in the scale. Moreover, the analysis of its reliability using Cronbach's alpha method of IBT and ITLS yield of index ato.942 and $\mathbf{0 . 9 6 4}$, which indicates a high level of internal consistency for scale in the questionnaires.

Since the data researcher obtained here was belonged to quantitative approach, I used questionnaires as the most common types of instruments used in survey research. After administering the tryout and analyzing the validity and the reliability, the results show that it was no need for the researcher to revise the items of questionnaires. Therefore, I was able to get the real data using that 


\section{JLIC}

questionnaire. I collected the data divided into two sessions. First session was used to collect data of 50 freshman students. Second session was used to collect data of 67 sophomore students. I went to teacher of the class to ask for help to spread the questionnaires to administer the survey at a prearranged time. I first briefly explained to the teachers the nature and the purpose of this study and provided instructions about how to answer the questionnaires. After giving brief explanation, I needed their help to explain to their students. The time for answering the questionnaires took about 50 minutes for both questionnaires. After they filled the questionnaire, the participants were asked to submit the questionnaires to analyze the data.

Likewise, the data analysis was carried out statistically using SPSS 22. Firstly, correlation analysis was performed to measure the relationship between students' beliefs on translation as a learning strategy and the use of it. Secondly, independent t-test was performed to compare the use of translation as a learning strategy between freshman and sophomore students.

\section{RESULTS AND DISCUSSION}

\section{The Correlation between Students' Beliefs on Translation as a}

\section{Learning Strategy and the Use of It}

To assess the correlation between students' beliefs on translation as a learning strategy and the use of it, it can be seen from table 1 that the Pearson correlation coefficient, r, is 0.851 , and that it is statistically significant $(\mathrm{p}=\mathrm{o.000})$. As showed in the figure that Pearson's $\mathrm{r}$ is close to 1 . This means that there is a strong relationship between students 'beliefs about translation and their use of translation as learning strategy. This means that changes in students' beliefs about translation are strongly correlated with changes in students' use of translation as learning strategy. 
Table 1. The Correlation Analysis between Students' Beliefs and Their Use of Translation As Learning Strategy

\begin{tabular}{lcc}
\hline Variable & Sig. & r \\
\hline $\begin{array}{l}\text { Students' beliefs } \\
\text { The use of translation }\end{array}$ & o,ooo & 0,851 \\
\hline
\end{tabular}

In addition, the table showed that Pearson's $\mathrm{r}$ is positive $(+)$. In the figure, the Pearson's $r$ value of 0.851 was positive. It assumes that students' beliefs increase in value, the students' use of translation as learning strategy also increase in value. Similarly, as one variable decreases in value, the second variable also decreases in value. This is called a positive correlation.

Moreover, I can find Sig. (2-tailed) value in the Correlations figure. This value tells us if there is a statistically significant correlation between students' beliefs about translation and their use of translation as learning strategy. The sig. (2-tailed) is o.oo which is less than 0.05. It indicates that there is a statistically significant correlation between between students' beliefs about translation and their use of translation as learning strategy. That means, increases or decreases in one variable do significantly relate to increases or decreases in second variable.

It can be concluded that there is significant positive correlation between students' beliefs about translation and their use of translation as a strategy. It also means that increases or decreases in students' beliefs do significantly relate to increases or decreases in the students' use of translation. It also means the higher the students' beliefs, the more the students use translation.

\section{The Different Use of Translation as a Learning Strategy by Freshman and Sophomore Students}

Independent t-test was addressed to complete the second research objective was about the difference in the use of translation as learning strategy between freshman and sophomore students. The results of the statistical analysis of the comparison in the use of 


\section{JLIC}

translation as a learning strategy by freshman and sophomore students are summarized in Table 2.

Table 2. The Result Of Independent Sample T-Test

\begin{tabular}{lccccc}
\hline Level & $\mathbf{t}$ & Mean & Sig. & M & SD \\
\hline Freshman & \multirow{2}{*}{2.247} & 98.8800 & \multirow{2}{*}{0,028} & 98.88 & 20.55 \\
Sophomore & & 91.5075 & & 91.51 & 12.47 \\
& & & & & \\
\hline
\end{tabular}

There are two variables which are one categorical, independent variable (freshman/ sophomore students) and one continuous, dependent variable (the use of translation as a learning strategy). It is found the difference mean score (sig<0.05) between freshman and sophomore students. There was significant difference in scores for freshman $(M=98.88, S D=20.55)$ and sophomore $[M=91.51, S D=12.47 ; t(75.42)=2.25]$.

It indicates that mean score of freshmen is higher than sophomore students. It is revealed that the significant difference is found in the use of translation as learning strategy between freshman and sophomore learners. It means that the different of level/ year of study of the students show different use of translation as learning strategy.

From the result, the participants seem to be overwhelmingly believe that translating helps them acquiring English language skills such as reading, writing, speaking, vocabulary, idioms, and phrases. The findings regarding the students' beliefs of the students about translation are parallel with the studies of Liao. Liao (2006) found that the participants believed translation helps them acquire English language skills such as reading, writing, speaking, vocabulary, idioms, and phrases. The Indonesian students' positive beliefs about translation as English learning strategy also consistent with the newest published research conducted by Aktekin \& Glienecki (2015), they found that plenty number of their participants endorsed that they believe translation plays a positive role in their English learning process. This current research proved 
that the Indonesian students denoted that translation plays the important role in their English learning process by facilitating them as a strategy to learn English.

In term of the use of translation as a learning strategy, the participants employ translation as a learning strategy to comprehend, remember, and produce English. This finding was somewhat consistent with Karimian (2013) which showed that Iranian students' make use of translation as a strategy to help them learn English in language learning process.

Based on these findings, in terms of the relationship between learners' beliefs and their strategy use, overall, students' professed beliefs on the IBT were greatly consistent with their described learning strategies on the ITLS. The results showed that there is a significant positive relationship between participants' beliefs about translation and their use of translation as English learning strategy. So, it can be inferred that students with more positive and stronger beliefs use translation strategy more often. In other words, students' preference for English learning will naturally affect strategies they choose to learn. To put in another way, it might also say that students' tendency to use translation as an English learning strategy is directly affected by various categories of beliefs they are holding. This result also confirms with Wenden's (1987) study illustrated how beliefs affected learners' choice of strategies, their attending pattern, criteria for evaluating the effectiveness of a language learning activity, and their planning priorities. In terms of the relationship between learners' beliefs and their strategy use, Liao (2006) stated that although individual variations did occur, overall, students' professed beliefs on the IBT were greatly consistent with their described learning strategies on the ITLS.

Given the importance of students' beliefs and opinions about vital aspects of teaching and learning strategies ( Al-Musawi, 2003), university teachers should be more attentive to student learning strategies for the use of translation in language learning, because the use of translation prevailed among student English learning in IAIN Jember, especially in the early years of language teaching. 


\section{JLIC}

Teachers may not need to prohibit student use of translation altogether and should be more aware of the instances when translation can be beneficial for students as they develop their English language skills and competencies.

Furthermore, regarding students' conflicting beliefs and various uses of translation as a strategy, teachers might suggest translation more for some learners than others, based on their cognitive styles and learning strategies. Since students have some conflicting beliefs about using translation, teachers may want to help students raise their level of conscious awareness about the advantages and disadvantages of translating, and to encourage them to view translation as an effective and efficient strategy but to use it with caution. At the same time, although students on different proficiency levels may use translation as a strategy differently, they should all be advised to stay away from the possible pitfalls of Li interference and word-for-word translations.

Additionally, it appears that different of level of the students show different students' use of translation in learning English. Given that freshman and sophomore students constitute participant of this study, the findings imply a limited ability to read, write, and speak English without translation, although some English teachers believe that it is necessary for students to use translation only at the initial stages of learning. A possible explanation for this phenomenon is the limited scope of authentic situations in which the student is involved during University study and thus is able to enhance their basic skills in English as a foreign language. In addition, because translation usually facilitates comprehension, it is expected that more advanced students used less translation, because they were more capable in English and hence relied less on the transfer of their first language. This result confirms with the early study from Chia and Chia (2001) explaining that less proficient English learners more frequently employed or benefited from translation strategies than their counterparts who were more proficient learners of English. This result also confirms with Husain's research (1995) suggested that using translation had 
highly positive effects on the low and intermediate proficiency learners, but it did not benefit higher level students. Another important finding is that the intermediate level students made more gains than those higher-level peers do, and the gains made by the lower level students were higher than those by the intermediate level students. In other words, the higher-level students benefit the least from translation use. However, this result of this current study against the results of Liao (2006) study that found no significant relationship between these variables.

In this regard, at the university level, it is believed possible and even necessary to use English without translation because students at that level are believed to know English well enough to improve their linguistic skills without their mother tongue being involved. Such a viewpoint, however, is often in conflict with students' perspective, based on the findings of this study that students draw on knowledge of their native language and rely on translation as they try to discover the complexities of English. As the findings in this study indicated, the use of translation could be a valuable resource or tool that can contribute to the development of various language skills. In fact, the strategic use of Li or translation would be helpful in developing students' reading efficiency and maintaining the flow of their conversation and writing tasks. Students' beliefs about language learning are often based on limited knowledge and experience, and these beliefs likely influence students' effectiveness in their learning. Thus, it is necessary to foster that EFL teachers have dominant roles in applying translation into L1 strategy in English classes.

\section{CONCLUSION}

\section{Conclusion}

This current study makes emphasis on greater understanding on translation as a strategy for English learning by putting the students' perception and strategies ahead. Evidence that these activities were not designed with the aim of preparing best translators as a profession, but to create better foreign language 


\section{JLIC}

learning via translation. Two research questions were addressed in this study.

The current study is carried out as an attempt to measure the relationship between students' beliefs on translation as a learning strategy and the use of it and to examine the influence of difference year of study on the use of translation as a leaning strategy. The statistical analysis shows that generally students' beliefs on translation as a learning strategy correlate with the use of translation as a learning strategy and further analysis shows that different year of study affects the use of translation as a learning strategy.

In terms of the relationship between students' beliefs and their strategy use, although individual variations did occur, overall, students' professed beliefs on the IBT were greatly consistent with their described learning strategies on the ITLS. It is found that students' beliefs about translation as English learning strategy were strongly related to their use of translation of English learning. In other words, the higher the students' beliefs, the more they use translation in learning English. The above analyses suggest those learners' beliefs about how translation can function in their English learning apparently influenced the kinds of translation strategies they chose to use.

The finding which is addressed to second research problem of this study involved that freshman students use more translation strategies to learn English in an EFL environment than sophomore students. It appears that different of level of the students show different students' use of translation in learning English. Based on this finding, it appears that students' academic level may affect their beliefs about translation and accordingly their strategy of using of translation.

\section{Suggestion}

The findings of this study suggest some pedagogical implication. It is pivotal for teachers to become aware of their students' beliefs. They should encourage their students to view translation as an effective strategy, to raise their level of conscious 
awareness about the pros and cons of translating and to use it cautiously and judiciously. Moreover, foreign language teacher educators and teacher trainers cannot afford to ignore these beliefs if they expect their students to be open to particular teaching methods and to receive the maximum benefit from them. They should explain to their students the most common misconception about translation is that there exists a simple "word-for-word" relation between any two languages, and that translation is therefore a straightforward and mechanical process.

In addition, this study also finds what translation strategies students tend to use. It might be beneficial for further researchers to examine how students translate to help them learn a foreign language skills, complements, or language components. For example, asking students to describe or think aloud how they go about doing mental translation when they comprehend or produce a foreign language text. This information about how language students use translation strategies to learn, instead of what translation strategies they use, may provide more insights into the role of translation in foreign language learning.

\section{REFERENCES}

Al-Musawi , N. M. ( 2003 ). The effect of student teaching programs in the College of Education at the University of Bahrain on students' beliefs about teaching and learning processes. Kingdom of Bahrain: Univer. Of Bahrain Press.

Aktein \& Gliniecki (2015).ELTsStudents' beliefs about and strategy use of translation. International Online Journal of Education and Teaching (IOJET), 2(1). 12-24.

Brooks, L.,\& Kimberly A. (2009). Adult learners' perceptions of the incorporation of their L1 in foreign language teaching and learning. Applied Linguistics 30(2), 216-235.

Chia, H.L., and H.U. Chia.(2001) 'English reading concepts held by Taiwanese EFL readers', English Teaching E Learning, 26(2), 23-44.

Husain, L. 1995 'Assessing the role of translation as a learning strategy in ESL', International Journal of Translation, 1(2), 5984 . 


\section{JLIC}

Karimian, Z. (2013). Students' use of translation as a learning strategy in EFL classroom. Journal of Language Teaching and Research, Vol. 4(3), 605-610

Kavaliauskienë , G. , \& Kaminskienë , L. ( 2007 ) The effect of individual differences on learners' translation beliefs in EFL learning. Kalbotyra , 57 (3) $132-139$.

Liao, P. S. (2006). EFL learners' beliefs about and strategy use of translation in English learning, RELC Journal, 37(2), 191-215

O'Malley, J. M. , Chamot , A. U. , Stewner. M , G. , Kupper ,L. , and Russo , R. P. ( 1985 ) Learning strategy applications with students of English as a second language . TESOL Quarterly,19, 557 - 584.

Prince, P. ( 1996 ) Second language vocabulary learning: the roleof context versus translation as a function of proficiency. The Modern Language Journal, 8o , 478 - 493 .

Wenden, A. (1987). How to Be a Successful Language Learner: Insights and Prescriptions from L2 Learners', in A.L. Wenden and J. Rubin (eds.), Learner Strategies in Language Learning (Englewood Cliffs, NJ: Prentice-Hall): 103-18. 